\title{
Project-Based Management Technique for Radiofrequency Spectrum Planning and Allocation Part Two: The Project Management Plan
}

\section{Andrew J Kerans SMIEEE}

School of Engineering and Physical Sciences

James Cook University

Townsville, Queensland, Australia

Summary-Spectrum Management is the regulatory action of defining the use of the radiofrequency spectrum. Often this requires the clearance of a large number of incumbent systems to make way for new technologies such as Fourth Generation Mobile Broadband (4G). While great economic benefits may be derived from the new technologies the clearance of any band will come at a cost. It is important both costs and benefits be quantified and compared. In many Administrations, including Australia, these processes are carried out without a defined project management structure. In a series of two papers the Authors combine over 40 years of radio systems and planning experience to suggest a methodology for project-based management of spectrum planning activities. This paper provides an outline of a recommended project management plan structure and references that may be useful to spectrum planners throughout ITU- Region 3; the Asia - Pacific.

Keywords-project based spectrum management; radiofrequency spectrum; spectrum planning; spectrum economics.

\section{Introduction}

Spectrum Management is the combination of engineering, economic and allocative inputs resulting in a given use (or combined uses) of the radiofrequency spectrum (the spectrum) (Kerans 2011). Access to spectrum is vital for any service that cannot, or chooses not to be, tethered to a cable or optic fibre, and is the carriage medium for the exponentially growing mobile broadband industry. The rapid growth of mobile broadband, and the use of these systems to provide internet access where it previously could not be supplied, has been an enabler for a myriad of associated small industries; thus spectrum access is a true large-scale multi-faceted economic enabler.

The services that need to make use of the spectrum are many fold: they include the RADAR systems that monitor air traffic, the fixed links that pipe data to mobile base stations and are as diverse as deep space 
communications systems and those that provide mobile communications to ships at sea in the High Frequency (HF) bands.

Mobile telephones have been with us since the early 80's, in Australia pushing aside aircraft navigation systems to access one of the first major spectrum band for GSM services. Recently the world's population has taken to mobile broadband in an unprecedented adoption of new technology. Mobile Broadband, the ability to access the internet and other services on a smartphone is reliant on spectrum - very large amounts of it and regulators globally are faced with the problem of finding this spectrum in the increasingly crowded electromagnetic space.

Mobile broadband is estimated to contribute $\$ 17.4$ Billion (in 2010 dollars) to Australia's economy (Deloitte Access Economics 2010) and is totally reliant on access to suitable radiofrequency spectrum. Globally, Mobile Broadband is seen as a key enabler in developing countries, both access to spectrum and adherence to standards being key issues to ensure economies of scale in the production of user equipment.

Turner (2009) states that in some cases project members hold the view “There is no point planning....”; which historically has been the view of many in the spectrum planning field.

However access to spectrum is becoming fraught with difficulty. More and more systems are becoming available, each requiring access to spectrum. This is occurring at a time when public demand for mobile broadband is growing exponentially. This demand for spectrum is displacing incumbent systems, many of which collectively have a high sunk value and corresponding high economic value to various elements of society.

The cost of moving systems currently dependent on spectrum to a more appropriate medium is also a barrier. One example is television broadcasting. In most cases a combination of fibre to the home (or FttH) combined with satellite retransmission where FttH is uneconomical is a viable delivery solution. This would free up much valuable UHF spectrum for mobile broadband. However the cost to re-engineer broadcasting is prohibitive unless different allocation models are explored.

In real terms the cost of a spectrum refarming project requiring four planners with an appropriate travel budget over three years would be $\$ 2.1$ million (based on total staff cost of $\$ 150,000$ per annum plus $\$ 100,000$ overheads per annum) however such a project has the ability to disrupt $\$ 300$ million of existing infrastructure but on the other hand return $\$ 600$ million (Plum Consulting 2012) to government in auction returns for the spectrum. In addition to real returns the economic stimulus can be measure in terms of $\$$ Billions.

In Australia refarming of this spectrum for mobile broadband could potentially also result in a $\$ 4$ Billion additional economic activity (based on Deloitte Access Economics 2010).

Spectrum is an intangible finite inexhaustible resource. Simply put it doesn't exist. What is licensed or allocated is the right to create an electromagnetic disturbance within a given frequency range. The power to regulate spectrum in Australia is given in law by the (Australian) Radiocommunications Act 1992. 
The regulation of spectrum requires change as technologies progress. In the current decade there is a strong demand for access to spectrum to provide mobile broadband data. To provide access to this spectrum the ACMA must undertake 'refarming' exercises which in the lower bands favoured for mobile broadband always require the re-planning of the technical characteristics of the allocation and the clearance of incumbent services.

\section{Spectrum Management}

In the Australian context, Spectrum Management is the science of moving spectrum to its highest value use in accordance with the ACMA Principles for Spectrum Management (ACMA Principles) (ACMA 2009). In undertaking this task and projects relating to it the ACMA contributes to the Australian economy in general and the communications economy specifically.

Regionally coordinated spectrum planning has delivered many wins. Recognising that harmonisation brings with it economies of scale and ease of roaming, the Asia Pacific Telecommunity (APT) has developed a plan for the $700 \mathrm{MHz}$ band that is now recognised as being superior to the US alternative. This band plan, developed through exhaustive regional cooperation, has now been adopted by many Administrations both in the Asia Pacific region but also in Latin America, with many African nations seriously considering its adoption.

The implementation of the plan however will be different in almost every case. One common theme will be complexity, both political and from an engineering perspective, as broadcasting services are cleared and relocated and the plan implemented. This process would benefit from a structured yet flexible project management methodology.

Figure 1 is a flowchart of a 'typical' spectrum planning project process. Projects may differ in complexity or the number of consultations undertaken. However as a general representation the flowchart is useful in understanding the process.

Figure 1 also only represents the externally facing facets of the project; internal processes are not represented but in the case of internal consultations have been previously described.

Not described is the environmental scan and engineering work which initially results in choosing the band under review, but in effect prejudges the outcome as only bands suitable for the proposed new application will be chosen. The consultation however is not 'token'; many changes to plans have been made in the past and indeed some processes have been discontinued because the highest value use was found to be in the incumbent use.

Pertinent to the management of the project are the stakeholders. Some will be for the project, usually those who will gain from access to the spectrum. Some will be against the project, usually incumbent operators; most will be knowledgeable about the subject; and nearly all will be able to influence it politically or via the media. 
It is not in the interests of incumbents likely to be moved from a band to cooperate in either domestic or international deliberations where their eventual loss of spectrum access is a likely outcome.

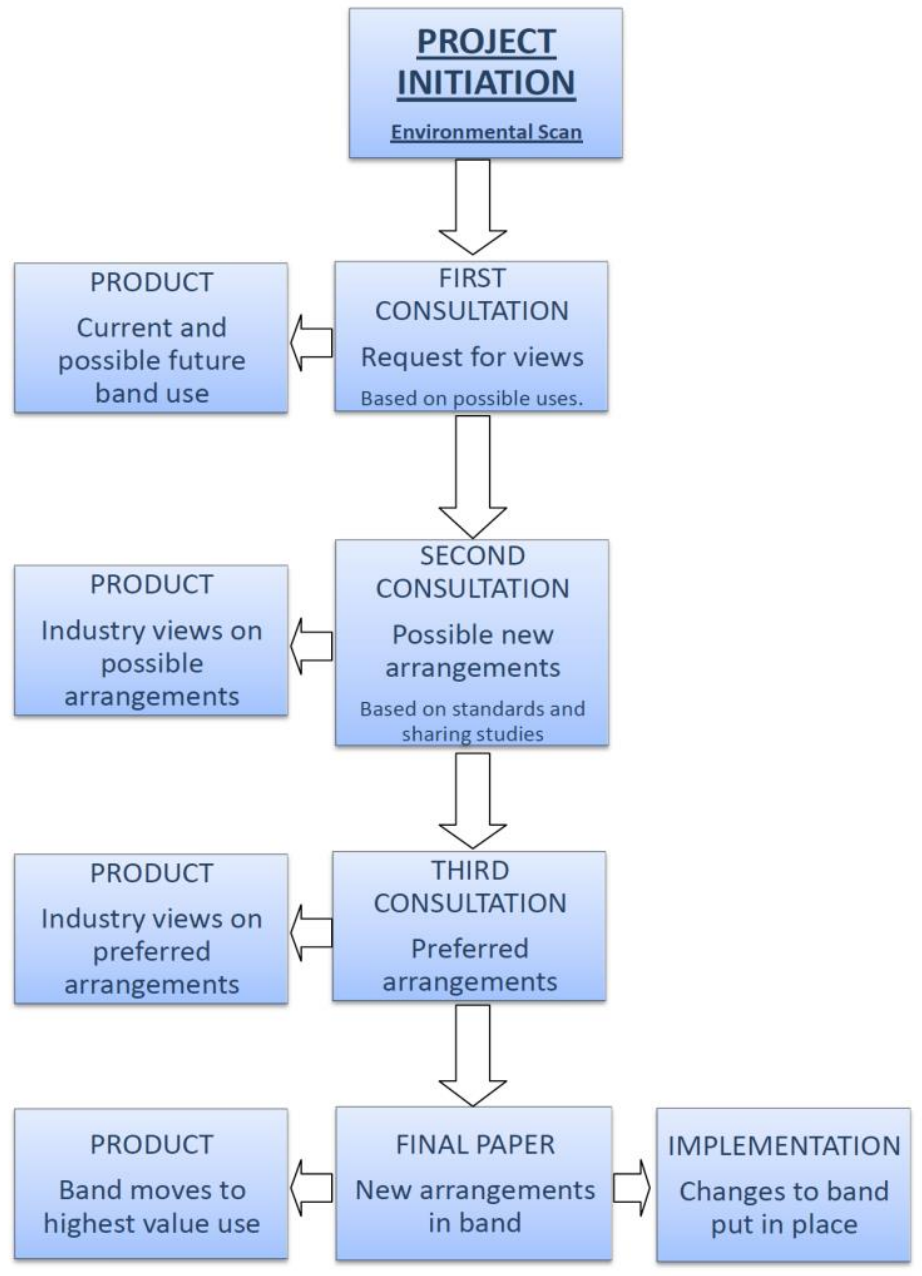

Figure 1. A Theoretical Spectrum Planning Process

\section{Stakeholder management}

Turner (2009) gives a good background in stakeholder identification and management which is particularly relevant to spectrum management both externally and internally within the ACMA. Stakeholder management thus represents a key area that would obviously need to be comprehensively addressed in any spectrum management project, and thus within each individual spectrum planning project management plan. 


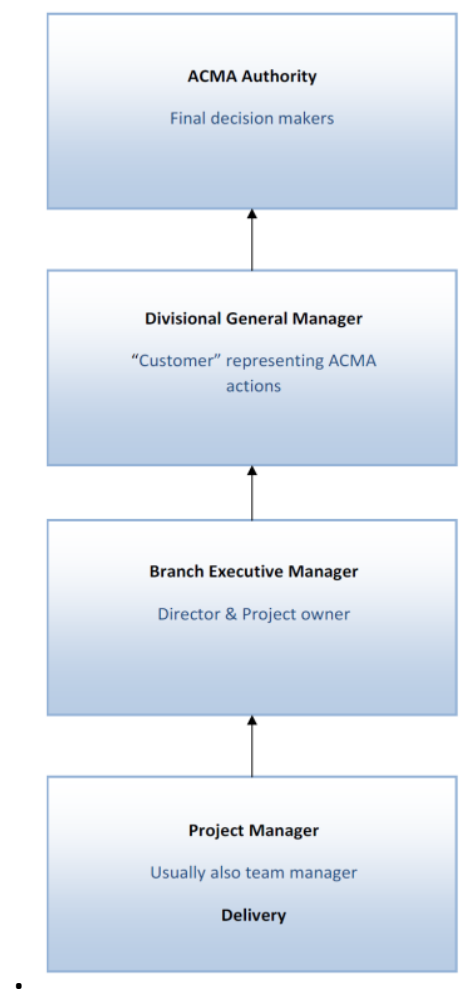

Figure 2. ACMA Decision Making Hierarchy

\section{Project based spectrum management}

Project Based Spectrum Management is a relatively new field. While various forms of project based management are used within the ACMA and undoubtedly within other spectrum management agencies there is no available literature on it.

Thus existing methodologies need to be examined, investigating their applicability to this reasonably wellknown but undocumented field.

The literature search undertaken as a part of this project did identify a number of things: Firstly spectrum project management has strong similarities with software management. There is a product that is intangible, there are customers and clients, and it is hard to make everybody happy. Secondly the work is often undertaken by multiple teams consisting of technical experts, and thirdly software projects are often 'accepted' by non-technical managers.

In general modern software projects are managed using 'PRINCE2 Methodology' (Office of Government Commerce 2009). PRINCE2 meets many of the requirements for management of projects where the outputs are not tangible; in fact if the outputs of the spectrum planning process are treated as 'products' then most of the methodology seems to fit well.

Spectrum planning is a step-wise process composed of iterative steps; each step informs the next and a true project path can never really be developed from the beginning. Thus some form of step-wise methodology is needed where multiple inputs can be used to inform the next stage. 
A variant of PRINCE2 methodology proposed for IT projects is called 'Step Wise Methodology' (Lu 2006) and potentially provides a good path for the development of a PRINCE2 methodology to inform spectrum project management.

One paper on software project management seems particularly relevant to spectrum projects; Barry W. Boehm in a paper entitled 'Theory-W Software Project Management: Principles and Examples' (Boehm 1989) presents some principles directly applicable to spectrum project management (direct quotes in italics). The title 'Theory-W: make everyone a winner' opens the abstract, a principle perhaps opposite to the reality of most regulators which can best be described as 'the role of the regulator is to make everybody equally unhappy'. In a process where one party covets that held by another and where a compromise is necessary it may be near to impossible to make everybody happy, but as a risk mitigation strategy and care in the development of a business case, it is a worthy goal.

Boehm also makes two 'subsidiary' statements: 'Plan your flight and fly your plan' and 'manage your risks'. Both of these 'adages' are excellent guidance for spectrum management. When a pilot 'plans their flight and flies their plan' there must always be room for flexibility when the weather fails to cooperate or quick action when an engine fails. The two statements also go hand in hand; a rigid flight plan will fail to manage risk. A rigid PMP will do likewise.

In PRINCE2 methodology (Office of Government Commerce 2009: pp 32-33 and Fig 5.2) a breakdown of various corporate structures is given. This is valid for the ACMA and the methodology can be modified to directly represent the reporting lines of the ACMA and similar Australian statutory bodies. Figure 2 shows a simplification of the ACMA structure along with project and decision making responsibilities.

In Australia and for the case of spectrum management the true client is the Australian Government; however in creating a Statutory Authority the Minister for Broadband Communications and the Digital Economy has delegated the stewardship of that role to the ACMA Authority who therefore become the client.

The Authority currently has little input to the project other than final decision making and delegates responsibility to the Divisional General Manager via legally binding delegations. Thus the Divisional General Manager is for all intents and purposes the customer.

Turner provides excellent guidance on the identification of interested parties (Turner 2009: pp 77-83). The ACMA organisation is what Turner calls a Coordinated Matrix (Turner 2009: p 126 \& Figure 6.2). Occasionally a 'secondment matrix' is used for major projects or where a project has failed. In general though Spectrum Management within the ACMA is a bureaucracy, spectrum planning is carried out by the engineers within the Spectrum Planning Branch, spectrum allocation within a Policy Branch and operational support, such as the mechanics of issuing an authorisation and interference investigations, within an Operations Branch. 


\section{Identifying stakeholders}

In a spectrum planning project as in construction or software projects, stakeholders are both internal and external. Because of the inherent differences between the two in a spectrum regulation environment these will be dealt with differently.

\section{Internal Stakeholders:}

Internationally the ACMA is recognised as a strong organisation, a world leader in spectrum management with a very good team spirit. The ACMA is a public service organisation, a term often unfairly maligned, with this in mind a quote from then U.S President John F. Kennedy about the 1960s US public service remains true today:

"You may have been told that government workers are clock-watchers; you will soon find that the vast majority of them are dedicated not to their paychecks but to the job to be done. You may have heard that government positions involve nothing but plodding routine tasks; you will see some of the most exciting, interesting work in the world being done here. You may have read that public servants are unimaginative, security seeking, uncreative, skilled only at the techniques of empire building; you will quickly discover that we have far more than our share of lively minds, endowed with vigor and courage." (Spelling and Grammar uncorrected US Style) (Rosen 1983).

Like any large bureaucracy the ACMA has internal politics - people who may gain from a project's failure, and this must be acknowledged and managed as outlined in an article 'Project Management: Still More Art Than Science' by Kate Belzer (2001).

Thus internal stakeholders, whether for or against the project, must be identified and communication with them managed. To quote an ACMA project manager when asked about why an earlier project; acclaimed as a 'jewel in the crown' of the ACMA during planning, failed to progress during the implementation phase: " $\mathrm{X}$ and Y set me up. They didn't want me running this so they didn't do the licence conditions we needed to get the incumbents cleared" (Gladman 2013).

Useful guidance on the management of internal stakeholders can be found in the 'Theory-W' paper (Boehm 1989) in guidance to 'make everyone a winner'. With internal stakeholders it is entirely possible to make everyone a winner and Boehm goes on to explain how (quotes in italics). In essence it involves carefully managed communications and some simple guidelines:

1) Separate the people from the problem.

2) Focus on interests, not positions.

3) Invent options for mutual gain.

4) Insist on using objective criteria. 
Within a public service structure profit is not a motivator, but kudos and prestige are, for both managers and teams, and working this into the project outcomes in a shared way in line with the guidance above is most likely to result in success.

In addition to not identifying internal stakeholders, beyond identifying them in 'contacts' the PMP does not outline what role a stakeholder may have in the process. In order to apply these principles, people with and interest and influence need to be identified along with their motivations.

While the 'difficult internal people' should not be identified as such in a plan available to all, they should be identified as having an interest in the project and from that a communications strategy formed. Turner (Turner 2009: Ch 4.2) provides excellent guidance on managing stakeholders which is pertinent to ACMA internal stakeholders. Again it rests on communications, but also when to communicate depending on each person's commitment to the project.

\section{External stakeholders:}

In a spectrum planning exercise external stakeholders fall into one of two categories: the incumbents who have an investment in the band under review and stand to lose if changes are made, and those vying for new services, usually telecommunications carriers and vendors, who stand to gain from an expanded market.

While Boehm's guidance to 'make everyone a winner' may not be possible where a stakeholder will be disadvantaged by change there are methods to salve the pain, such as incentive auctions for spectrum, where the incumbent bids against the new entrant and if they lose, some of the money goes to the incumbent.

\section{Risk management}

In spectrum planning work the risk may be multi-tiered. There is risk to the project, it might fail. There is risk to the ACMA's reputation, it might be sullied. Finally there is risk to the Government, and if they perceive this then the risk to the ACMA's existence becomes a reality. So in any risk strategy multiple tables will be needed and an aggregate score developed that correctly identifies the total risk and where it emanates from.

There are other risks to a spectrum planning project beyond stakeholder reaction. In brief these could include a lack of applicable equipment standards, loss of trained personnel, an incorrect cost benefit analysis or inappropriate input from other areas of government (see an article in The Australian Newspaper by Bingemann (2012), for example). Risks are multiple and multi-faceted in any spectrum project and must be properly identified and defined, and from this a risk management plan developed.

Both PRINCE2 and the PMBOK Guide (Project Management Institute 2008) give guidance on risk management. It is probably simpler to look at a single 'standard' and PRINCE2 seems to have the most applicability to spectrum projects. The PRINCE2 manual (Office of Government Commerce 2009: p78) gives the following guidance on risk management (paraphrased quotes in italics). 
- $\quad$ Establish Goals and Context

- Identify Risks

- $\quad$ Analyse Risks

- $\quad$ Evaluate Risks

- $\quad$ Determine the Treatments for the Risks

- $\quad$ Avoiding the risk by discontinuing the activity that generates it.

- $\quad$ Reducing the likelihood of the occurrence.

- $\quad$ Reducing the consequences of the occurrence.

- Transferring the risk.

- $\quad$ Retaining the risk.

- Monitor and Report on the effectiveness of Risk treatments

At first glance all are appropriate except perhaps 'transfer the risk'. However even this could be given consideration. Should an external agency threaten the project by, for example providing poor advice to the Minister, then a strategy for informing the Minister that the ACMA does not agree would transfer the risk of project failure from the ACMA to the other agency. This should of course be thought of as a last resort; a comprehensive communications strategy with the Minister's Office may be able to prevent such problems developing.

\section{Critical path analysis}

In a fully developed set of deliverables in a spectrum project, some work packages will rely on the outcome of a previous process or product. In its initial stages a spectrum management project is sold as an 'open' consultation where all possibilities are considered. This of course is not the case; early work in an environmental scan, a cost benefit analysis and a determination of the need for spectrum for a certain application would have identified candidate bands. From these, and depending on the urgency of the need, bands that are easily converted are chosen. Thus, while the initial consultation may ask questions like: 'The ACMA seeks comment on the proposed objectives of the review' (ACMA 2011), the outcome, at least in part is predefined by the initial work.

Because a likely path is known, a critical path at least containing initial products and bodies of work can be developed with possible paths leading from it. From this review stages can be planned and the critical path updated with known information and reviewed.

An excellent guide to using a Critical Path Method in a complex project environment is presented by $\underline{\text { Stelth }}$ and Roy (2009). This paper analyses the application of critical path management throughout a changing and complex project. Hill, in 'The Complete Project Management Methodology and Toolkit' (Hill 2009) provides an initial methodology for developing the critical path. These references combined provide sufficient information for the development of a flexible CPA capable of meeting the needs of project managers during a constantly changing spectrum planning project.

AUSTRALIAN JOURNAL OF TELECOMMUNICATIONS AND THE DIGITAL ECONOMY VOLUME 2 NUMBER 4, DECEMBER 2014

ISSN 2203-1693. Copyright (C) 2014 The Author(s). http://doi.org/10.7790/ajtde.v2n4.60 
The potential for change during the term of a spectrum project is dependent on the initial cost benefit analysis. If the analysis suggests the benefits are close to the costs then the potential is high. On the other hand if the benefits far outweigh the costs, even with a reasonable allowance for uncertainty the potential for a change of direction is low.

Most bands where the costs and benefits were widely spaced in favour of change have already been refarmed; these were the 'low fruit' of spectrum management. The task now gets harder as the gap between cost and benefit narrows, thus the potential for a change in direction has increased and will continue to in the future.

In a paper on the integration of PRINCE2 and a methodology known as SCRUM (Rankins \& Kearns 2008) describes how the two methods can be defined to commence a project before all requirements are known by being agile and open to change during the project. SCRUM is defined on Wikipedia:

'Scrum is an iterative and incremental agile software development framework for managing software projects and product or application development. Scrum focuses on project management institutions where it is difficult to plan ahead. Mechanisms of empirical process control, where feedback loops that constitute the core management technique are used as opposed to traditional command-and-control management' (Wikipedia 2013).

The combination of methods seems useful in the case of spectrum management projects and could be used to enhance a spectrum PMP.

\section{A new spectrum project model}

Spectrum planning has been shown to be a complex process, one where stakeholder management is generally the key, and poor stakeholder management can result in project failure or damage to the ACMA's reputation. Beyond the importance of the project is the importance of the Australian economy, poor spectrum planning can have a serious detrimental effect on the wellbeing of all Australians: imagine living in a country without access to mobile data. So getting it right is paramount and to re-quote the famous adage: 'if you fail to plan you plan to fail'.

In this section recommendations are made for the transformation of spectrum planning project management into a professional activity that produces an economy stimulating resource and minimises the risk of failed outcomes.

To begin the recommendations resulting from this report a diagram of a more holistic, but generalised spectrum management project is presented. This is presented here so that it can be referred to in subsequent sections. The flowchart is by no means comprehensive; spectrum planning projects differ in many ways and only a thorough pre-analysis can possibly describe all necessary elements. Figure 3 is therefore presented here as guidance only, a basis or foundation on which to build a complete picture. 
The second recommendation resulting from the development of a business case would be the target audience. The ACMA Authority currently spends time 'editing' and then approving consultation papers during the life of the project, finally approving the changes needed to implement the recommended outcome. Preparation for Authority is time consuming and uses resources that could be better used on the project itself. This report recommends that the business case be developed in a way as to allow the Authority to approve the project as a whole so that a single full-time Authority member can take oversight and that the project can then proceed to final recommendation without further Authority scrutiny.

Spectrum Planning Project management has been described in previous sections; while the project-based management of spectrum planning activities is an emerging field, the projects themselves are not dissimilar to other projects. The outputs from a spectrum planning project are discussion papers, decision papers and technical frameworks; these are tangible products similar to the code in a software project.

Figure 1 describes a very high level, or helicopter view of a spectrum planning project. Indeed this is the only level the final decision makers within the ACMA actually see. Figure 3 presents another generic flow chart of a spectrum planning project, this visualisation of a spectrum project where the activities of Figure 3 along with the preparation of technical frameworks are subsumed within a single work-unit "Commence Spectrum Planning Project”.

This flowchart may be useful when used to produce a thorough Project Management Plan (PMP) as it outlines each stage in each inter-related process providing a guide to ensure nothing is missed.

\section{Approval processes.}

The first layer of the flowchart is the business planning process, culminating (hopefully) in the approval of the project. The process as shown is a recommendation; that is a business plan is prepared for each project and submitted to the ACMA Authority (or equivalent) for approval.

Following that, the ACMA Authority (or equivalent) is 'kept informed' to a level depending on the sensitivity of the project, this level being determined in the communications strategy, but does not make further approvals until the final recommendations are presented. This is not the method currently used and there may be resistance to this recommendation from managers or the Authority, as in the case of the latter it loosens their control and in the case of the former increases their responsibilities.

The recommendation has the benefit of seeking a single level of project approval, with review, removing the necessity for multiple papers with supporting documentation being submitted. On an average spectrum planning project this could save as much as $30 \%$ of the total work hours as well as some travel expenses for attendance at Authority meetings. 


\section{The project management plan.}

In Figure 3 the development of the PMP is shown as a single work unit. This is not the case - the actual PMP is a combination of all of the processes shown which result in the work unit 'commence spectrum planning project'.

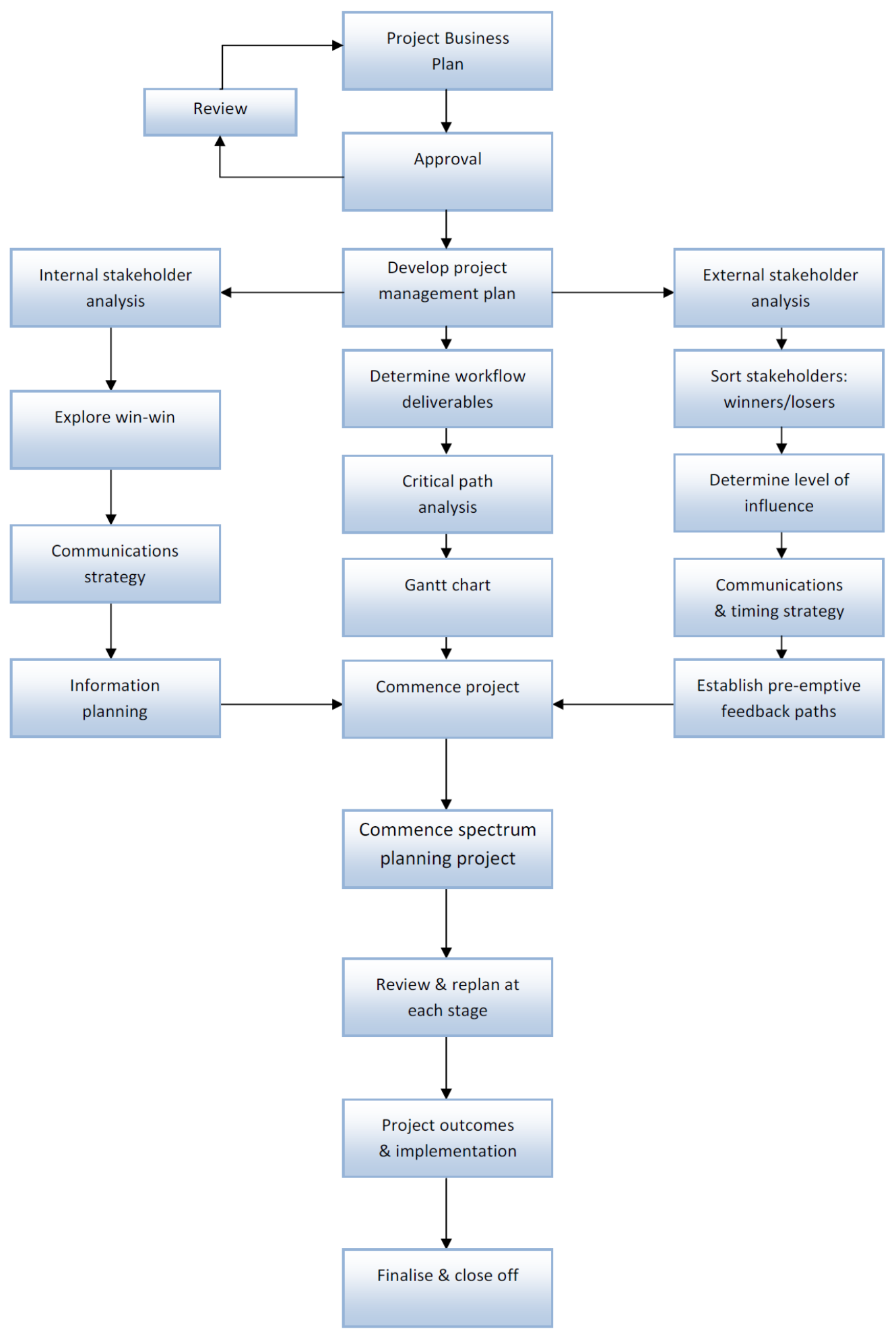

Figure 3. A new spectrum project model. 
The importance of stakeholder identification, stakeholder sorting and a cross referenced communications plan has been discussed. These processes are depicted in each of the outriggers to the PMP development cycle. With internal stakeholders the philosophy of 'make everyone a winner' can be used and a strategy developed around that so as to eliminate or minimise disruption or the risk of failure caused by internal politics.

Making every external stakeholder a winner to the same extent is probably not possible in a spectrum planning project, however various methods have been described that may reduce the loss in the case of incumbents. The economic aspects of these should have been considered in the business planning stage, meaning the PMP development will have tighter guidance on what outcomes need to be planned for.

Using this information a communications strategy matrix can be developed outlining which external stakeholder is told what and when in the lead-up to a fully open public discussion process. By using time, message and strategy the impact of the main risk, political interference resulting from lobbying, can be minimised.

During this phase a multi-tiered risk management matrix should be developed which identifies all elements of risk to the project, to the ACMA and to Government. Most of the risk will pertain to a communications strategy but some may not. Until identified these risks cannot be mitigated.

\section{Monitoring the project.}

The PMP, like a flight plan, needs to be flexible because 'stuff happens'. The 'review and re-plan' work item in Figure 3 reflects this. When stuff does happen a review may be required and changes to the plan, timelines, staffing or budget necessitated. Stuff could also mean more briefings, additional consultation, more economic analysis or even discontinuing the project. The ability to incorporate these changes is an important aspect of the development of the PMP.

\section{Implementation.}

A few ACMA planning projects have failed because the implementation process failed. The reasons for the failure have been touched on - good communications with internal stakeholders and a project based structure would have pre-empted them. So, assuming all managers and staff are on board, up to speed and ready because the inclusion and communications strategy has worked, implementation is simply the project moving away from the planners to operational staff but still within the core of the project.

\section{Close off.}

There are very few lessons learned in spectrum planning processes because often the close off is not documented. This should become an integral part of any project so that those following can benefit. Beyond that criteria are needed to decide when a project ends. Following a reallocation the band may still be encumbered, so 'all legacy systems cleared and the band reallocated' could be a good start. However there 
will always be residual encumbrances, so this is impractical. Exactly when it is beyond the scope of this report, but as a measurable it is important or projects may develop their own lives and unnecessarily consume resources and therefore it should be developed within the PMP.

\section{Overall recommendations.}

The overarching recommendation of this paper is that spectrum regulators develop a spectrum planning project management methodology for each spectrum planning project, based on recognised methodology or combinations of methodologies such as PRINCE2 and PMBOK. This methodology should take into account the communications strategies necessary for managing a diverse group of stakeholders as outlined in the referenced literature.

The second recommendation is that project closure studies should be conducted for all major spectrum projects and the lessons learned made available through the literature, so that all regulators can learn and improve their respective methodologies.

\section{References}

Australian Communications and Media Authority (ACMA). 2009. Principles for spectrum management [online] Available at: http://www.acma.gov.au/Industry/Spectrum/Spectrum-planning/About-spectrumplanning/principles-for-spectrum-management

Australian Communications and Media Authority (ACMA). 2011. The 9oo MHz band-Exploring new opportunities, Available at: http://www.acma.gov.au/theACMA/submissions-to-the-900-mhzbandexploring-new-opportunities-ifc-142011

Belzer, K. 2001. 'Project Management: Still More Art Than Science', PMForum Newsletter, June 2001.

Bingemann, M. 2012. 'Conroy's wireless spectrum reserve slammed as 'unworkable", The Australian [online], 15 December, Available at http://www.theaustralian.com.au/australian-

it/telecommunications/conroys-wireless-spectrum-reserve-slammed-as-unworkable/story-fn4iyzsr1226537177347 [Accessed: 15 Jan 2013].

Boehm, B.W. 1989. 'Theory-W Software Project Management: Principles and Examples', IEEE Transactions on Software Engineering, Vol. 15, No. 7, pp. 902-916.

Deloitte Access Economics. 2012. Mobile Nation: The economic and social impacts of mobile technology, Report for the Australian Mobile Telecommunications Association, Available at:

http://www.amta.org.au/pages/State.of.the.Industry.Reports

Gladman, K. 2013. ACMA Policy Officer. Interview January 2013

Hill, G.M. 2009. The complete project management methodology and toolkit, CRC Press, United States. 
Lu, KM. 2006. 'A new stepwise project management method', International Journal of Information Technology and Management, Volume 5, Issue 2/3, June 2006, pp 212-225.

Kerans, A. 2011. Radio Spectrum Planning, Does it Matter in Industry? Presentation to IEEE North Qld Section November 2011, Available from author at andrew.kerans@acma.gov.au

Office of Government Commerce. 2009. Managing Successful Projects with PRINCE2 2009 Edition Manual, 2009 Edition, The Stationery Office, Great Britain.

Plum Consulting. 2012. Valuation report for additional spectrum in the $700 \mathrm{MHz}$ and $2.5 \mathrm{GHz}$ bands, Report for the ACMA, London (not publicly available).

Project Management Institute. 2008. A Guide to the Project Management Body of Knowledge: PMBOK Guide, 4th Edition, Project Management Institute Inc., United States.

Rankins, G. J; Kearns, M. (no relation to author). 2008. 'Integrating PRINCE2 and SCRUM for successful new product development', presented at the Australian Institute of project management National Conference, Canberra, ACT, Australia, 13-15 October.

Rosen, B. 1983. 'Who Needs Bureaucrats?-In the National Interest', The Bureaucrat-The Journal for Public Managers, Vol. 12, No.1, pp. 41-42.

Stelth, P; Roy, GL. 2009. 'Projects' Analysis through CPM (Critical Path Method)', School of Doctoral Studies (European Union) Journal, No. 1, July 2000, pp. 10-51.

Turner, RJ. 2009. The handbook of project based management, 3rd edn, McGraw Hill, United States. Wikipedia.2013.http://en.wikipedia.org/wiki/Scrum_(software_development) 